\title{
Domino liver transplantation using FAP grafts. HUC experience - hopes and realities
}

\author{
A.J.L. Furtado \\ Unidade Polivalente de Transplanta o dos Hospitais da Universidade de Coimbra, Portugal \\ KEY WORDS: domino liver transplantation, familial amyloid polyneuropathy
}

ABBREVIATIONS: $\quad \mathrm{FAP}=$ familial amyloid polyneuropathy; $\mathrm{TTR}=$ transthyretin; $\mathrm{OLTx}=$ orthotopic liver transplantation; $\mathrm{DLTx}=$ domino liver transplantation

\section{SUMMARY}

Domino liver transplantation using FAP livers (DLTx/FAP) has become a worldwide strategy that is contributing significantly to the increase in liver grafts offered in Portugal. The safety of the procedure both in the FAP donors and in the recipients is emphasized in the series of 64 DLTx/FAP that has already been performed in the Hospital of the University of Coimbra (HUC). The occurrence of amyloidosis in the long-term survivors after DLTx/FAP is a serious possibility, although after 6 and 7 years post-transplant no symptoms have been reported by any of the patients. Indeed, amyloid deposits, although small, have been found in the skin and nerve biopsies of the first domino recipients (HUC unpublished data). Hopes that the disease will have a slow course in non-genetically affected patients still awaits the proof of time. Thus, DLTx/FAP should be considered an experimental procedure, although there is good reason to expect that the amyloidosis in the DLTx/FAP recipients will have a longer time course than in the genetically affected donors. The ethical implications of all these facts and expectations are discussed. A case by case approach is recommended. In such an approach, individual prognosis, urgency, graft shortage and the will of very well-informed patients or their legal representatives are determinants for judicious decisions when considering DLTx/FAP in patients under 50 years of age.

\section{Introduction}

$\mathrm{O}$ rthotopic liver transplantation (OLTx) for familial amyloidotic polyneuropathy (FAP) patients was first proposed by Holmgren et al, in 1990'. This was a major hope for changing the prognosis of the fatal course of this hereditary disease. Indeed, no other therapy has yet shown any promise of halting the inexorable evolution to death of FAP patients, whatever the mutation involved ${ }^{2}$. OLT $x$ with non-FAP liver grafts suppresses the major source of the abnormal protein (the FAP liver itself) which is at the center of the amyloidogenic process that ultimately leads to the polyneuropathy.

The main pools of FAP are found in Portugal, Sweden and Japan. In these communities, the ATTR Val30Met variant is prevalent. In Portugal, where the disease was first unveiled and characterized by Corino de Andrade in the $1960 \mathrm{~s}^{3}$, the Val30Met TTR gene mutation is almost exclusive. Although the disease is systemic, the liver functions are not usually affected. To our knowledge, not a single case of liver failure due to FAP has ever been described in Portugal.

In 1995, we began using the livers removed from FAP patients (while undergoing OLTx) as grafts for some selected non-FAP patients ${ }^{4}$. Originally, we named this procedure sequential liver transplantation but it became most often reported as domino liver transplantation (DLTx/FAP).

In the Transplant Unit of the Hospital of the University of Coimbra (UPT/HUC), a total of 62 patients have undergone this procedure. An overview of this series is presented below. Initial hopes and present realities are discussed.

Correspondence: Dr. A.J.L. Furtado, Hospitais da Universidade de Coimbra, 3000—075 Coimbra, Portugal

Fax:351-239-828622 E-mail: Ifurtado@huc.min-saude.pt 


\section{Rationale and ethical problems}

These grafts resume the production of the abnormal protein as soon as they become revascularized. The main rationale basis for this innovative procedure is that, in genetically affected patients, there is no clinical expression of the disease under the age of 20 years $^{5}$ (usually more than 25 in the Portuguese population), the disease is not clinically relevant before 30 and rarely fatal under 35 . Thus, it is reasonable to expect that, in non-genetically affected patients who receive FAP livers, the disease, if it appears, would follow the same or an even slower course than in the FAP patients. So, if a non-FAP patient receives a FAP liver graft at 50 and develops FAP, he would not die from this disease before 85 years of age. As the offer of cadaveric grafts always falls short of the needs, using FAP livers in patients included on long waiting lists could significantly shorten the waiting time for OLTx, both in FAP and non-FAP patients.

FAP grafts offer the advantages of living grafts absence of ischemic injury related to the death of cadaveric donors, short ischemic times, programmed selection of the pair donor-recipient and, as a result, enhanced chances of immediate better function. Another unique advantage of these grafts is that they are the only available whole grafts in the living set, although, obviously, they may also be used as reduced or split grafts ${ }^{6-10}$.

Two main ethical principles must preside in the DLTx/FAP procedure: it should not add any risk to the FAP donors and a detailed informed consent of the patients or of their legal representatives must be obtained. Information on the experimental character of the procedure and on the possibility of the appearance of polyneuropathy in the recipients is mandatory.

\section{Material and methods}

Sixty-two patients aged $28-63$ years received 64 DLTx/FAP. General demographics are presented in Table 1 , and the indications for transplant in Table 2. The implantations followed the classic technique (nonpreservation of the recipient $\mathrm{s}$ vena cava) in patients with malignancies close to the vena cava $(1 \mathrm{~cm}$ or less). A

Table 1. Characteristics of DLTX/FAP patients (HUC series, Oct. 1995-Dec. 2002)

\begin{tabular}{llll}
\hline Recipients & 62 & DLTx & 64 \\
Male & 48 & Female & 14 \\
Age (years) & $28-63$ (med. 50) & & \\
\hline
\end{tabular}

piggy-back technique was used (with two exceptions) in patients with tumors located far from the vena cava and in patients with benign pathology. An external veno-venous by-pass was always used during the FAP patient $s$ hepatectomy and in the recipient when the retrohepatic vena cava was not preserved (mainly tumors). Thirteen DLTx/FAP recipients, unanimously considered to have extremely bad prognoses, were under 45 years of age (Tables 3 and 4). In three cases, combined DLTx/FAP with split allowed transplantation in 3 recipients starting with only one cadaver graft.

\section{Results}

Survival curves for the domino recipients and the grafts are shown in Figure 1.

Three patients required retransplantation (4.7\%): two of these patients had two consecutive DLTx/FAP: a 53year-old alcoholic and HCV cirrhotic woman who developed and died of sepsis, and a 55-year-old HVB cirrhotic man who developed fulminant liver failure, 1 month after the first DLTx/FAP; he is very well 4 years later. The third patient lost his DLTx/FAP graft because of hepatic artery thrombosis (9th post-operative day of DLTx/FAP); for

\begin{tabular}{lrcr}
\hline \multicolumn{3}{l}{ Table 2. Indications for DLTx/FAP (HUC series) } \\
\hline Malignant pathology & 26 & Benign pathology & 36 \\
Hepatocellular carcinoma & 18 & Cirrhosis & 28 \\
Neuroendocrine tumor & 5 & Alcoholic & 14 \\
Metastasis carcinoma colon & 1 & Viral & 11 \\
Others & 2 & Other cirrhosis & 3 \\
& & Acute liver failure & 4 \\
& & Chronic rejection & 1 \\
& Others & 3
\end{tabular}

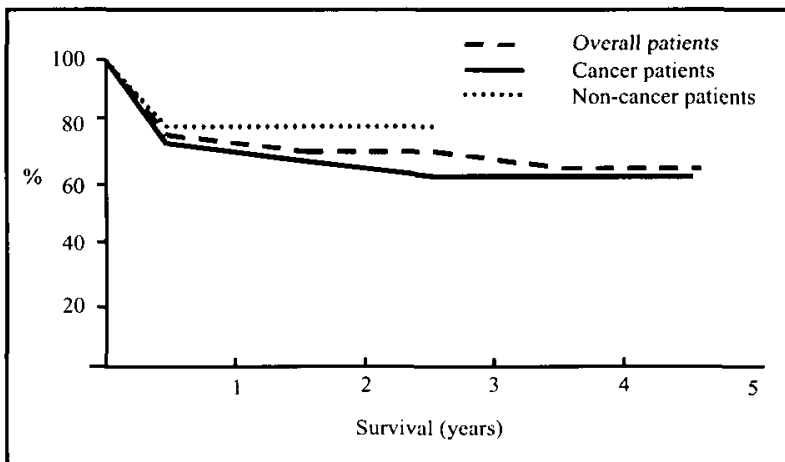

FIGURE 1: Actuarial survival curves for DLTx/FAP recipients. 
Table 3. Exceptional indications ( $>40$ years $<45$ years -6 recipients)

\begin{tabular}{llll}
\hline Age & Pathology & Alive & Dead \\
\hline 44 & Hepatocellular carcinoma - portal thrombosis & 37 months \\
45 & Hepatocellular carcinoma ( $\alpha 1$-antitrypsine deficiency + pulmonary fibrosis & 12 months \\
45 & Hepatocellular carcinoma (alchoholic cirrhosis) & 10 months \\
45 & Neuroendocrine tumor (kidney Tx) & 31 months \\
& Alcoholic cirrhosis (doubtful compliance) & 10 months \\
44 & Wilson cirrhosis (coma, acute respiratory distress syndrome) & Brain death \\
\hline
\end{tabular}

Table 4. Exceptional indications ( $<40$ years -7 recipients)

\begin{tabular}{|c|c|c|c|}
\hline Age & Pathology & Alive & Dead \\
\hline 33 & Hepatocellular carcinoma & & 1 year - recurrence \\
\hline 28 & $\begin{array}{l}\text { Hemolysis, elevated liver enzymes, } \\
\text { low platelet syndrome (HELLP) - 3rd Tx }\end{array}$ & & 2 months - multiple organ failure \\
\hline 33 & Acute liver failure - 3rd Tx & & $\begin{array}{l}\text { Chronic rejection. Death } \\
\text { at } 39 \text { months. Refused } R e T x\end{array}$ \\
\hline 29 & Hemangiosarcoma & & 4 months - Met \\
\hline 35 & Crypt C (Jehovah's Witness) & 2 years - very well & \\
\hline 34 & Acute liver failure - primary non-function - 2nd Tx & 10 months - very well & \\
\hline 39 & Acute liver failure - primary non-function - 2nd Tx & & 35 days - sepsis \\
\hline
\end{tabular}

logistic reasons, he was retransplanted with a cadaver graft and is well at 4 years post-transplantation. The outcomes of the 13 recipients aged less than 45 years, whom we considered to have exceptional indications, are included in Tables 3 and 4.

\section{Discussion}

Organ shortage is the main cause of long waiting times for OLTx of many patients who, meanwhile, see their clinical condition worsening or even die. Since our original report of the first DLTx/FAP4, the procedure has gained wide acceptancell. Early on in our experience, we were confronted with clinical situations that prompted the change of the original indications we had established for advising the procedure: malignant pathology in recipients above 50 years.

The absence of any FAP symptoms or electromyographic changes, along with the slow deposition of amyloid in the skin or in the sural nerves of the patients who received DLTx/FAP 6 to 7 years ago, underline the expectation that amyloidosis in the recipients of FAP livers would not be a problem for the great majority of these patients. The risks of recurrence of the original disease (malignancies, viral hepatitis, alcoholic recidivism, etc.) and the negative impact of the immunosuppression, probably represent greater risks than the risks of dying of FAP, at least in patients over 40 years. The advantages of using the livers of FAP patients seem indisputable. They are further emphasized in countries with many FAP patients awaiting OLTx as their only hope of stopping the course of the disease. The opportunities for OLTx of FAP patients on long waiting lists which include many other non-FAP liver patients became more and more a problem in Portugal. In the UPT/HUC series, DLTx has been very well accepted, both by FAP and nonFAP patients, who realized the mutual benefits of that strategy. This has meant that most of the FAP patients transplanted in our Unit during recent years were domino donors who, otherwise, would have been transplanted later or who would not have been transplanted at all. Since the beginning of its practice, DLTx/FAP has contributed $16 \%$ of the total grafts used in our series of 500 liver transplants. Improvements in logistics and cooperation between centers may allow an increase of this contribution to $25-30 \%$. 
Establishing a guide to the lower age limit for DLT $x / F A P$ candidates is a relevant but not an easy issue to solve. Some exceptional cases must be approached on an individual basis, perhaps with the contribution of ethical committees. Deciding factors range from the willingness of the candidate to be transplanted as early as possible to the urgency of the situation. When dealing with malignancies or viral and alcoholic cirrhosis, we propose DLTX/FAP strategy for patients over 40 years. Some very special situations may justify or even impose resorting to DLTx/FAP; this is the case in young patients with very bad prognoses at short- or mid-term in whom a second or third non-FAP graft would not be provided. Our experience, shown in Tables 2 and 3, seems quite explicit some cadaveric grafts would have been wasted if they had not been used in FAP patients, but a few patients would not have been saved if it were not for the possibility of DLTx/FAP. In the group of patients between 40 and 45 years of age (Table 3 ) the prognosis of the four survivors is rather uncertain ( 3 cancers). The mortality in the group under 40 years (Table 4) shows clearly that they were patients with extremely bad prognoses. The indications for DLTx/FAP in the only two survivors were, in one patient, a deliberate option to assure the best initial function in a very difficult transplantation in a Jehovah $s$ Witness 12 with no blood transfusion allowed (dismissed from the hospital - day 11) and, in another patient, a primary non-function (PNF) after a failed first cadaveric transplant (acute liver failure, unknown etiology); in this case and at the time the super-urgent call was issued, the only available graft was a FAP patient s liver. Extreme organ shortage may justify DLTx/FAP in patients even younger than those we have transplanted 10 .

The survival curves in this series are almost exclusively related to crucial factors of the recipient pathology (severity of the disease, comorbidity, general condition, etc.). Indeed, the series includes a high percentage of very high-risk or desperate cases. Only one graft loss was ascribable to technical failure (hepatic artery thrombosis). No cases of PNF occurred in this series. The low retransplantation rate $(4.7 \%)$ further emphasizes the excellent quality of these grafts. This was the main reason for preferring DLT $x /$ FAP in the very difficult case of transplantation in a young Jehovah s Witness, with prohibition of using blood or blood derivatives ${ }^{12}$.

\section{Conclusions}

DLTx/FAP is a strategy definitely established as a safe procedure both for FAP donors and for non-FAP recipients. Initial very good function of the graft and very low probability of PNF are the rule. Morbidity and survival rates are mainly related to the recipient s pathology. The development of FAP after DLTx/FAP is to be expected in some long-living recipients. Thus, clinical indications (mainly taking into account some crucial factors such as age, urgency and prognosis) imply difficult ethical considerations derived from the possibility of FAP development in the recipients. A detailed informed consent and team discussion are key elements to judicious decisions before indicating this procedure, which must still be considered experimental.

\section{References}

1 Holmgren G, Steen L, Ekstedt J, Groth CG, et al. (1991). Biochemical effect of liver transplantation in two Swedish patients with familial amyloid polyneuropathy (FAP-met 30). Clin Genet 40, 242-246

2 Ericzon BG, Suhr O, Broome U, Homgren G, Duraj F, Eleborg G, Wikstrom L, Norden G, Friman S and Groth CG (1995). Liver transplantation halts the progress of familial amyloidotic polyneuropathy. Transplant Proc 27, 1233

3 Andrade C (1963). Clinique de la Paramyloidose du type portugais. Acta Neuropathol (suppl II), 3-11

4 Furtado A, Tom L, Oliveira FJ, Furtado E, Viana $\mathbf{J}$ and Perdigoto R (1997). Sequential liver transplantation. Transplant Proc 29, 467-468

5 Monteiro E, Perdigoto, R and Furtado AL (1998). Liver transplantation for familial amyloid polyneuropathy. Hepatogastroenterolgy 45, 1375-1380

6 Furtado L, Oliveira F, Furtado E, Geraldes B, Reis A, Viana J, Bento C, Vieira H and Neves S (1999). Maximum sharing of cadaver liver grafts - Composite split and domino liver transplantation. Liver Transplant Surg 5, 157-158

7 Stangou AJ, Heaton ND, Rela M, Pepys MB, Hawkins PN and Williams $R$ (1999). Domino hepatic transplantation using the liver from a patient with familial amyloid polyneuropathy. Transplantation $65,1496-1498$

8 Azoulay D, Castaing D, Adam R, Mimoz O and Bismuth $\mathrm{H}$ (2000). Transplantation of three adult patients with one cadaveric graft: wait or innovate. Liver Transplant 6, 239240

9 Furtado, AJL (2000). Domino liver transplantation using livers from patients with familial amyloid polyneuropathy. Curr Opin Organ Transplant 5, 69-73

10 Inomata $Y$, Nakamura T, Uemoto S, Tanaka K, Wakabayashi $G$ and Shimazu M (2000). Domino split-liver transplantation from a living donor: case reports of in-situ and ex-situ splitting. Liver Transplant 7, 150-153

11 FAPWTR: Familial Amyloidotic Polyneuropathy World Transplant Register (2000). Update. Huddinge University Hospital - Sweden

12 Furtado AJL, Furtado ES-B, Geraldes JB, Oliveira FJ, Perdigoto R, Viana J and Otero M (2001). Sequential liver transplantation in a Jehovah s witness. Arquivos Portugueses de Cirurgia 10,38-41 
Copyright of Amyloid is the property of CRC Press LLC and its content may not be copied or emailed to multiple sites or posted to a listserv without the copyright holder's express written permission. However, users may print, download, or email articles for individual use. 